This is the peer-reviewed version of the following article: Juliana Utley. "Construction and Validation of Geometry Attitude Scales.” School Science and Mathematics 107, no. 3, p. 89-93, which has been published in final form at https://doi.org/10.1111/j.1949-8594.2007.tb17774.x. This article may be used for non-commercial purposes in accordance with Wiley Terms and Conditions for Use of Self-Archived Versions.

\title{
Construction and Validation of Geometry Attitude Scales
}

\author{
Juliana Utley \\ Oklahoma State University
}

\begin{abstract}
The purpose of this study was to develop and establish the validity and reliability of an instrument to measure students' attitudes toward geometry. Participants consisted of 264 undergraduate students from two universities, one in the Midwest and one in the Southwest. The instrument is a 5-point Likert-scaled survey consisting of 32 statements and 3 subscales. The internal consistency using Cronbach's coefficient alpha was 0.95 for the confidence subscale, 0.93 for the usefulness subscale, and 0.92 for the enjoyment subscale. For the overall instrument using the 32 items that comprised the three subscales, internal consistency reliability analysis revealed a Cronbach's coefficient alpha of 0.96. Additionally, this article reports on the content, criterion, and construct validity of the instrument.
\end{abstract}

Key Words: Attitudes toward Mathematics; Geometry; Affective; Attitude scale

Affective variables such as attitudes toward mathematics are related to the learning of mathematics and to the learning environment in a classroom (Reyes, 1984). Current reform efforts in mathematics education call for students to be active participants in the learning process and for solving nonroutine problems. While it has been pointed out that this type of environment 
supports student construction of knowledge and organization of their thoughts (Wheatley \& Abshire, 2002), these changes may conflict with students' attitudes toward mathematics. According to McLeod (1994), this type of reform should improve student interest and enjoyment of studying mathematics. Therefore, to improve the learning of mathematics it is important to study students' attitudes toward mathematics (Fennema \& Sherman, 1976; Reyes, 1984).

Children begin to develop an attitude toward mathematics as soon as they are exposed to mathematics and these attitudes can have an affect on students learning in mathematics. For example, it has been shown that some students are prohibited from learning mathematics to their full potential due to a negative attitude toward mathematics (Reyes, 1980). Ma and Kishor (1997) conducted a meta-analysis of 113 studies that investigated the relationship between attitudes toward mathematics and achievement in mathematics and found this relationship to be both reliable and positive, but not strong. McLeod (1992) suggests that attitude toward mathematics and achievement in mathematics are not dependent on each other, but that they "interact with each other in complex and unpredictable ways" (p. 582). While overall measures of attitude toward mathematics have only small positive relationships with achievement, a measure of a student's confidence in mathematics has a relatively strong positive correlation with achievement in mathematics (e.g. Dowling, 1978). It has been shown that when students are more sure of themselves that teachers seem to pay more attention to them (Reyes, 1980).

While the measurement of attitudes toward mathematics can be determined through direct observation, interviews, questionnaires, and student drawings and writings, Aiken (1985) points out that attitude scales are the most popular, objective and efficient in collecting attitude data. The Dutton Scale (Dutton, 1954) was one of the earliest instruments used and it measured feelings toward arithmetic. A variety of other instruments have been constructed to measure 
either one dimension of attitude (e.g. Dowling, 1978, Plake \& Parker, 1982) or multiple dimensions (e.g. Fennema \& Sherman, 1976; Tapia, 2004). These instruments are designed to measure dimensions such as enjoyment of mathematics, value of mathematics, mathematics anxiety, attitude toward success in mathematics, mathematics as a male domain, effectance motivation, usefulness of mathematics, parent/teacher expectations, and confidence to learn mathematics.

While there are many scales that measure various dimensions related to a variety of attitudes toward mathematics in general, there is a need for instruments that are content specific. It is not uncommon to hear a student say that they like mathematics but dislike geometry or algebra. Thus, it is the belief of this author that it is important to have an instrument that specifically measures the attitudes of students toward geometry. Thus, the purpose of this study was to develop an instrument to measure students' attitudes toward geometry. A secondary purpose was to establish the validity and reliability for the Utley Geometry Attitude Scale (UGAS).

\section{Method}

\section{Participants}

Participants consisted of 264 undergraduate students (85 male, 174 female, and 5 that did not report their gender) from two universities, one in the Midwest and one in the Southwest. Of the respondents, $81.5 \%$ were Caucasian, $5.7 \%$ were Native American, $4.9 \%$ were Hispanic, $4.2 \%$ were African American, 1.9\% were Asian, and 1.9\% described themselves as other. Participants ranged in age from 18 to 48 with an average age of 21.4 years. Approximately $50 \%$ of the participants were education majors with the remaining $50 \%$ of the participants indicating a wide 
variety of majors including, but not limited to, Agricultural Economics, Aviation, Business

Management, Fire Protection, Pre-Law, Pre-Med, and Zoology.

\section{Measures}

Utley Geometry Attitude Scales. The UGAS was developed after extensive review of a variety of existing instruments used to measure attitudes to mathematics (e.g. Akin, 1974; Dowling, 1978; Fennema \& Sherman, 1976; Tapia, 1996) and was designed to measure the attitudes of undergraduate college students toward geometry. The instrument is a 5-point Likertscaled survey consisting of 32 statements, seventeen positively and fifteen negatively worded. Participants' responses can range from strongly disagree to strongly agree. Negatively worded items were recoded prior to analysis. The instrument is designed such that higher scores are more indicative of an overall higher attitude toward geometry. Illustrative items are "I am positive that I can learn geometry concepts" and "Time drags during geometry class."

Fennema-Sherman Mathematics Attitude Scales. Three of the nine subscales from the Fennema-Sherman Mathematics Attitude Scales (FSMAS) (Fennema \& Sherman, 1976) were used to help establish criterion validity of the UGAS. These three subscales included the confidence in learning mathematics scale, the mathematics usefulness scale and the effectance motivation scale. Each scale consists of 12 questions, 6 positively and 6 negatively worded, on a 5-point Likert-type scale. Participants' responses can range from strongly disagree to strongly agree. All negatively worded items were recoded prior to analysis. Scores on each subscale can range from 12 to 60 and the higher the score, the more positive the attitude. Fennema and Sherman (1976) reported split-half reliabilities of 0.93 for the confidence in learning mathematics subscale, 0.87 for the effectance motivation subscale, and 0.88 for the usefulness of mathematics subscale. They reported the instrument to be a valid and reliable instrument. This 
instrument has been used extensively in the research literature as a measure of attitudes toward mathematics. Illustrative items are "Generally I have felt secure about attempting mathematics" and "I study mathematics because I know how useful it is."

\section{Procedure}

Participants were informed of the purpose of the study and solicited to participate. All participants were informed that there would be no penalty for refusal to participate in the study and those agreeing to participate were ensured the confidentiality of their responses. Participants were asked to complete both the UGAS and the FSMAS during the same time period. Although participants were not given a time limit, all participants were finished completing both surveys within a half hour. Those participant surveys with items unanswered were eliminated from the analysis. In addition to the two surveys, demographic information was collected from each participant.

\section{Results}

\section{Validity}

Content validity. A panel of five experts, two mathematics faculty and three-mathematics education faculty, with knowledge of geometry and its teaching were asked to evaluate the appropriateness and relevance of each item on the instrument. Based upon comments and suggestions from this panel a few minor changes were made and content validity was again evaluated by the panel of experts prior to the first administration of the instrument.

Criterion validity. The criterion-related or more specifically the concurrent validity of the UGAS and its three subscales was assessed by correlating them with the FSMAS and three of its subscales. A strong positive correlation $(r=.702, p<.001)$ was found between the UGAS and the FSMAS. In addition, strong positive correlations were found on the corresponding 
confidence subscales $(r=.651, p<.001)$, on the corresponding usefulness subscales $(r=.670, p$ $<.001$ ), and between the enjoyment scale of the UGAS and the effectance motivation scale of the FSMAS $(r=.658, p<.001)$.

Construct validity. Construct validity was assessed using a factor analytic method. Exploratory factory analysis using principal components analysis with a direct oblimin oblique rotation was used to identify the potential factors or subscales for the 32-item instrument. Data were analyzed using SPSS based on the 264 usable surveys. The factor analysis revealed a list of four factors with eigenvalues above 1.0 (see Table 1). In addition to looking at eignevalues greater than 1.0, Gorsuch (1983) recommends evaluating the scree plot and whether the factors are interpretable. Based on these three criteria, it was determined that three factors should be retained.

Table 1. Total of variance explained in the EFA for factors whose eigenvalues exceed 1.00.

\begin{tabular}{lccc}
\hline Factor & Eigenvalue & \% of Variance & Cumulative \% of Variance \\
\hline 1 & 15.66 & 48.94 & 48.94 \\
2 & 3.29 & 10.28 & 59.22 \\
3 & 1.59 & 4.98 & 64.20 \\
4 & 1.03 & 3.22 & 67.42 \\
\hline
\end{tabular}

A second principal components analysis was performed using an oblique direct oblimin rotation and three factors. Since an oblique rotation was used both the rotated pattern matrix and the structure matrix were examined (Hetzel, 1996). A clear, interpretable three factors appeared and accounted for $64.20 \%$ of the variance. The first factor accounted for $48.94 \%$ of this variance and appeared to focus on the usefulness of studying geometry. The second factor accounted for $10.28 \%$ of the variance and seemed to deal with confidence in learning geometry. The third factor accounted for $4.98 \%$ of the variance and appeared to focus on the enjoyment of working geometry problems. 
Next, the items were examined to determine whether they loaded on one factor and whether they had a factor loading greater then 0.30 (Kline, 1994/2000). These factor loadings are shown in Table 2. Additionally, each item was evaluated according to how well it fit a particular factor. Ten items $(2,10,12,17,19,20,24,26,28,31)$ loaded solely on the first factor (usefulness of geometry), twelve items (1, 5, 8, 9, 11, 13, 18, 21, 22, 27, 29, 32) loaded solely on the second factor (confidence in learning geometry), and ten items $(3,4,6,7,14,15,16,23,25$, 30) loaded solely on the third factor (enjoyment of geometry).

Table 2. Factor Pattern Matrix after Direct Oblimin Rotation with three factors.

\begin{tabular}{|c|c|c|c|}
\hline \multirow[b]{2}{*}{ Survey Item } & \multicolumn{3}{|c|}{ Factor } \\
\hline & 1 & 2 & 3 \\
\hline 1. I am sure that I can learn geometry concepts. & .267 & -.618 & -.006 \\
\hline 2. I believe that I will need geometry for my future. & .863 & -.108 & -.112 \\
\hline 3. Geometry problems are boring.* & .001 & -.009 & .685 \\
\hline $\begin{array}{l}\text { 4. When I leave class with a geometry question } \\
\text { unanswered, I continue to think about it. }\end{array}$ & .079 & .156 & .720 \\
\hline 5. I often have trouble solving geometry problems. ${ }^{*}$ & -.055 & -.786 & .101 \\
\hline $\begin{array}{l}\text { 6. When I start solving a geometry problem, I find it } \\
\text { hard to stop working on it. }\end{array}$ & -.009 & .036 & .673 \\
\hline 7. Time drags during geometry class.* & .101 & -.014 & .659 \\
\hline $\begin{array}{l}\text { 8. I am confident I can get good grades in geometry. } \\
\text { 9. When I can't figure out a geometry problem, I feel }\end{array}$ & .031 & -.744 & .071 \\
\hline as though I am lost and can't find my way out.* & .104 & -.779 & -.223 \\
\hline 10. Geometry has no relevance in my life.* & .803 & -.035 & .049 \\
\hline 11. I lack confidence in my ability to solve geometry problems.* & .064 & -.848 & .006 \\
\hline 12. Geometry is not a practical subject to study.* & .595 & -.137 & .116 \\
\hline 13. I feel sure of myself when doing geometry problems. & .029 & -.775 & .124 \\
\hline 14. Geometry is fun. & .182 & -.204 & .612 \\
\hline $\begin{array}{l}\text { 15. I just try to get my homework done for geometry class } \\
\text { in order to get a grade.* }\end{array}$ & -.010 & -.022 & .588 \\
\hline 16. Geometry is an interesting subject to study. & .233 & -.266 & .559 \\
\hline $\begin{array}{l}\text { 17. I can see ways of using geometry concepts to solve } \\
\text { everyday problems. }\end{array}$ & .590 & -.034 & .190 \\
\hline $\begin{array}{l}\text { 18. For some reason even though I study, geometry seems } \\
\text { unusually hard for me.* }\end{array}$ & -.045 & -.910 & .026 \\
\hline 19. Geometry is not worthwhile to study.* & .706 & -.055 & .104 \\
\hline 20. I often see geometry in everyday things. & .580 & -.013 & .209 \\
\hline 21. Geometry problems often scare me.* & -.049 & -.905 & -.042 \\
\hline $\begin{array}{l}\text { 22. I am confident that if I work long enough on a } \\
\text { geometry problem, I will be able to solve it. }\end{array}$ & -.098 & -.632 & .158 \\
\hline
\end{tabular}


23. Solving geometry problems is enjoyable.

24. I will need a firm understanding of geometry in my future work.

25. Working out geometry problems does not appeal to me.*

26. I do not expect to use geometry when I get out of school.*

27. Geometry tests usually seem difficult.*

28. I will not need geometry for my future.*

29. I can usually make sense of geometry concepts.

30. Geometry has many interesting topics to study.

31. Geometry is a practical subject to study.

32. I have a lot of confidence when it comes to studying geometry.

\begin{tabular}{lll}
-.003 & -.192 &. $\mathbf{7 3 3}$ \\
& & \\
$\mathbf{. 8 6 4}$ & .046 & -.026 \\
.131 & -.296 & $\mathbf{. 5 9 6}$ \\
$\mathbf{. 9 2 6}$ & -.002 & -.043 \\
-.003 & $\mathbf{- . 8 1 5}$ & .034 \\
$\mathbf{. 7 9 2}$ & .125 & .005 \\
.078 &.- .777 & .053 \\
.146 & -.158 & $\mathbf{. 6 3 6}$ \\
$\mathbf{. 5 1 7}$ & -.148 & .225 \\
-.035 & $\mathbf{- . 8 2 3}$ & .134 \\
\hline
\end{tabular}

Note: Loadings on the pattern matrix $>0.30$ are in bold. *Item is recoded prior to scoring.

\section{Item-Total Correlation}

In order to determine whether any of the statements on the survey were problematic, a correlation between each statement and the total score was computed. This was done for the survey as a whole and for each of the subscales. The corrected item-total correlations ranged from 0.47 to 0.83 for the entire scale, 0.61 to 0.85 for the confidence subscale, 0.65 to 0.85 for the usefulness subscale, and 0.51 to 0.83 for the enjoyment subscale. Since the elimination of none of the statements from the subscales would increase the value of the Cronbach's alpha by much for that subscale or the entire survey, no statements were eliminated from the survey. Robinson, Shaver, and Wrightsman (1991) suggested that all corrected item-total correlations less than 0.30 should be deleted; however, upon inspection all were well above this value.

\section{Reliability}

A measure of internal consistency was calculated for the UGAS and each of its subscales. The internal consistency using Cronbach's coefficient alpha was 0.95 for the confidence subscale, 0.93 for the usefulness subscale, and 0.92 for the enjoyment subscale. For the total 
UGAS score using the 32 items that comprised the three subscales, internal consistency reliability analysis revealed a Cronbach's coefficient alpha of 0.96.

\section{Summary}

Three subscales were identified as confidence to learn mathematics, usefulness of studying geometry, and the enjoyment of studying geometry. The 32 item instrument showed to have good internal reliability. Additionally, the UGAS appears to be a valid instrument. It should be emphasized that this instrument has been found to be reliable for undergraduate students. The reliability of this instrument needs to be tested for use with school age students or other potential populations.

Information gained from the UGAS can provide educators with a useful means of assessing their students' attitudes toward geometry. By examining the overall responses of students, educators can gain a general sense of their attitude and then by examining scores on the individual subscales they can gain an understanding of their students' confidence to learn geometry, usefulness in studying geometry, and enjoyment to learn geometry. These scores can be used to examine a variety of relationships such as the relationship between students' attitudes and achievement in geometry or between students' attitudes and student/teacher interactions.

This instrument focused on three dimensions of attitude. While this instrument measures three dimensions of attitude, attitudinal research is concerned with more than just these three constructs. Thus, future research should focus on the potential for additional subscales such as anxiety, motivation, and parent/teacher expectations to be developed and used in conjunction with these subscales to measure overall attitude. Additionally, studies should be conducted to determine whether a difference is found between a participant's attitude to mathematics and more specifically their attitude toward geometry. 


\section{References}

Aiken, L. R. (1974). Two scales of attitude toward mathematics. Journal for Research in Mathematics Education, 5, 67-71.

Aiken, L. R. (1985). Attitude towards mathematics. In T. Husen \& T. N. Postlethwaite (Eds.), The international encyclopedia of education: Research studies, Vol. 6 (pp. 3233-3236).

Dowling, D. M. (1978). The development of a mathematics confidence scale and its application in the study of confidence in women college students. Unpublished doctoral dissertation, Ohio State University, Columbus.

Dutton, W. H. (1954). Measuring attitudes toward arithmetic. Elementary School Journal, 54, 24-31.

Fennema, E. \& Sherman, J. A. (1976). Fennema-Sherman mathematics attitudes scales: Instruments designed to measure attitudes toward the learning of mathematics by females and males. JSAS Catalog of Selected Documents in Psychology, 6, 31.

Gorsuch, R. L. (1983). Factor analysis (2nd ed.). Hillsdale, New Jersey: Lawrence Erlbaum Associates.

Hetzel, R. D. (1996). A primer on factor analysis with comments on patterns of practice and reporting. In B. Thompson (Ed.), Advances in social science methodology (Vol. 4, pp. 175-206). London: JAI Press.

Kline, P. (2000). An easy guide to factor analysis. London: Routledge. (Original work published 1994).

Ma. X., \& Kishor, N. (1997). Assessing the relationship between attitude toward mathematics and achievement in mathematics: A meta-analysis. Journal for Research in Mathematics Education, 28, 26-47.

McLeod, D. B. (1992). Research on affect in mathematics education: A reconceptualization. In D. A. Grouws (Ed.), Handbook of research on mathematics teaching and learning (pp. 575-596). New York, NY: Macmillan Publishing.

McLeod, D. B. (1994). Research on affect and mathematics learning in the JRME: 1970 to the present. Journal for Research in Mathematics Education, 6, 637-647.

Plake, B. S., \& Parker, C. S. (1982). The development and validation of a revised version of the Mathematics Anxiety Rating Scale. Educational and Psychological Measurement, 42, 551-557.

Reyes, L. H. (1984). Affective variables and mathematics education. Elementary School Journal, $84,558-581$. 
Robinson, Shaver, and Wrightsman (1991). Measures of personality and social psychological attitudes. San Diego, CA: Academic Press.

Tapia, M. (1996, November). The attitudes toward mathematics instrument. Paper presented at the annual meeting of the Mid-South Educational Research Association, Tuscaloosa, AL.

Tapia, M., \& Marsh II, G. E. (2004). An instrument to measure mathematics attitudes. Academic Exchange Quarterly, 8(2), 16-21.

Wheatley, G. H., \& Abshire, G. E. (2002). Developing mathematical fluency: Activities for grades 5-8. Tallahassee, FL: Mathematics Learning. 